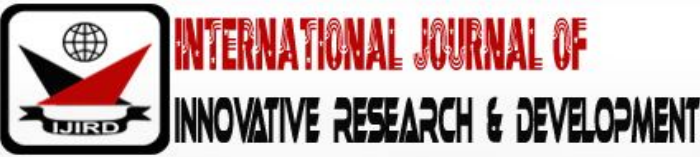

ISSN 2278 - 0211 (Online)

\section{Human Capital and Customer Service on Performance of Public Hospitals in Kirinyaga County, Kenya}

\author{
Milcah Waithaka \\ Student, School of Business, Kenyatta University, Kenya \\ Elias Njagi \\ Lecturer, School of Business, Kenyatta University \\ David Kiiru \\ Lecturer, School of Business, Kenyatta University
}

\begin{abstract}
:
Organizations differ in terms of availability, amount and quality of strategically relevant intangible resources. The extent to which these resources can translate into superior performance in specific organizations is still not well understood by most organizations. Most Sub-Saharan African countries are constrained by resource scarcity which undermines the implementation of decentralized public services. In competing with other public services for scarce resources, the health sector is often ranked relatively low among national development priorities. According to the Ministerial Strategic Plan 2014/18, challenges in the Kenyan health environment include limited resources, inefficiencies in utilizing available resources and weak regulatory systems. This study sought to investigate the effect of human capital and customer service on the performance of public hospitals in Kirinyaga County, Kenya. The study was anchored on the Resource Based View and Institutional theory. The study used descriptive research design and targeted 92 respondents drawn from 23 departments in the respective four public hospitals. A census was carried out and data was collected through structured questionnaires, analyzed through descriptive and inferential analysis and reliability checked using Cronbach's alpha reliability index. The study established that human capital and customer service had a positive significant effect on performance of public hospitals in Kirinyaga County. The study concluded that hospitals that invest in human capital and customer service will perform better than those who do not. The study recommended further studies on the resources with the use of a moderating factor.
\end{abstract}

Keywords: Human capital, customer service, performance

\section{Introduction}

Even as countries strive to expand health care access or institute forms of universal coverage, infrastructure issues are making it increasingly difficult for public health care systems to sustain current levels of service and affordability. Governments and health systems throughout the world continue to implement cost-containment measures aimed at reducing clinical and administrative waste and improving operational efficiency. Common tactics used include standardizing clinical processes to better coordinate and distribute responsibilities among departments and using resources more efficiently. Others have shared services centres for back office support such as information technology (IT), human resources (HR), finance, technology-assisted service provision and delivery methods which include e-prescriptions, novel payment cards, patient administrative systems, electronic medical records (EMRs), personal health records and telemedicine.

Most Sub Saharan African countries are constrained by resource scarcity which undermines the implementation of decentralized public health services. In competing with other public services for scarce resources, the health sector is often ranked relatively low among national development priorities. In 2001, the heads of states in the African Union committed themselves to allocate 15 percent of their national budget to health in the Abuja Declaration. However, this commitment has not been realized by the majority of the countries (Kaseje, 2006).

According to the MOH- AWP 2017-18 budget report, the key outputs that the Kenyan Government plans to deliver in the 2017/ 18 Financial Year include ensuring access to maternal health, modern diagnostic and treatment services and quality healthcare services. Digitization of public health facilities and equipping public hospitals are amongst the projects being undertaken. According to the current budget, the allocation will be used to acquire resources which will in turn affect the performance of the public hospitals. 


\subsection{Organization Performance}

Organization performance is the extent at which an organization meets its strategic objectives and other results as appropriated in the organization's policies. Performance indicators are numerical information that quantifies input, output and dimension of process and outcome. (Barney and Clark, 2007). Hospital performance may be defined according to the achievement of specified targets, either clinical or administrative. Ultimately, the goal of health care is better health, but there are many intermediate measures of both process and outcome. Targets may relate to traditional hospital functions, such as diagnosis, treatment, care and rehabilitation as well as to teaching and research. Hospital performance may thus be expected to include elements of community care and public health, as well as social and employment functions. These dimensions of hospital performance have been analysed in the European context (Healy and McKee, 2002).

Performance assessment of public hospitals based on intangible resources looks at the performance indicators that are influenced by the particular resources that the hospital adopts. This means that areas of considerations will include how human capital and customer service contribute to the performance of the particular hospital. Delivering quality service based on performance has significant relationship with customer satisfaction, employee satisfaction, loyalty, costs, profitability, service guarantees and growth of organization (Sohail, 2003).

\subsection{Human Capital}

Human capital is described as the collective value of the organization's intellectual capital which includes competencies, knowledge and skills. This capital is the organization's constantly renewable source of creativity and innovativeness. Hospitals are a healthcare producing firms with one of the inputs to a hospital production function being human capital. Human capital can be gained through education, internship, experience, competence and sharing and it is expected that a firm should perform better when its employees have more human capital. In a hospital, human capital extends from specialists, through nurses to support staff. Staffs with greater experience are capable of providing quality healthcare services which translate into reduced mortality and quick response in service provision (Liu, Timothy and Gao, 2010)

Human capital is developed for specific tasks, not only in clinical procedures, but also in team organisation and functioning within a specific hospital and unit. The human capital generated in hospital units through experience can spill over to new members of the team because they can learn from older members and also innovations in organisation can be shared. Thus, there should be a general accumulation of human capital over time, leading to increased productivity over time (Stiles and Kulvisaechana (2003).

\subsection{Customer Service}

Customer service is the process of making a consumers aware of services and products available and providing them with what they need to their satisfaction. Customer service aims to introduce a substantial yet different presence of a good or service that will draw customers and keep them loyal. Since the markets have become competitive, institutions even the health care ones are striving to offer products and services that are unique so as to satisfy the customers. The institutions must also align themselves with what is happening globally and produce goods and services that have a global market value (Rafati, Zargar and Dehghan, 2005).

Customer service is a practise that joins many stakeholders. It serves to make known an organization's output, to make a company known for its services, invoke what a customer wants and fulfil the dreams of investors. According to the Parasuraman model, the process of appraising a product is not as complex as evaluating a service. This is because services are intangible, inseparable, variable, perishable and heterogeneous. Services also do not have one criterion for measurement since they are judged based on the verdict of consumers who may have different interpretations and judgments of one particular service. Measures of quality customer service include tangibility, reliability, responsiveness, assurance and empathy (Marshall and Murdoch, 2001).

\section{Statement of the Problem}

A study done by Boshoff and Gray (2004) reveals that patients perceive health care workers as unresponsive during their interaction with them in the course of seeking treatment. Muga (2005) shows that some of the constraint faced in the health sector include decline in expenditure, inefficient utilisation of resources, centralized decision making, inequitable management information systems, out-dated health laws, inadequate management skills at the district level, worsening poverty levels, increasing burden of disease and rapid population growth.

According to the Kenyan Healthcare Sector Market Study Report (2016), Kenya has a high health worker shortage, mostly affecting the rural areas. Most health workers are employed in the private sector, in which the competition for doctors drives the costs of healthcare. This brings a challenge of improving the capacity of training, efficiency of health workers, and reducing the so-called brain-drain where trained health workers look for greener pastures in the private sector and abroad.

A report by PBB (2015) has revealed that the performance of public health sector in Kirinyaga County has been facing challenges leading to poor service delivery of health care. Challenges experienced during budget implementation include: Many health facilities are not adequately equipped according to norms and standards; inadequate budgetary provisions for the procurement and distribution of essential health products and technologies and existence of disparities in the distribution of existing health workers, where arid and semi-arid areas are disadvantaged with less staff. Since the above challenges pertain to the physical resources available to public hospitals, this study sought to investigate how human capital and organizational 
capital available to the public health sector in Kenya affect performance with specific reference to public hospitals in Kirinyaga County.

\section{Objective of the Study}

The general objective of the study was to examine the effect of human and organizational capital on performance of public hospitals in Kirinyaga County, Kenya.

\subsection{Hypothesis}

The specific hypothesis formulated for the study were:

- $\quad \mathrm{H}_{1}$ There is no significant effect of human capital on the performance of public hospitals in Kirinyaga County, Kenya

- $\mathrm{HO}_{2}$ There is no significant effect of customer service on performance of public hospitals in Kirinyaga County, Kenya

\section{Literature Review}

\subsection{Theoretical Framework}

\subsubsection{Resource Based View Theory}

The origins of the Resource Based View (RBV) can be found in the works of Penrose (1959). Emphasis was put on the importance of resources and its implications for the firm performance. The supporters of this view argue that organizations should look inside the company to find the sources of competitive advantage. When a resource exhibits value, rarity, imitability, and non- substitutability (VRIN) attributes, it enables the firm gain competitive advantage. Resource based theory as a basis for competitive advantage of a firm lies primarily in the application of a bundle of valuable resources at its disposal (Barney and Clark, 2007).

A subsequent distinction purports that the encompassing construct previously called resources can be divided into resources and capabilities. In this respect, resources are tradable and non-specific to the firm while capabilities are firm specific and are used to engage the resources within the firm such as the implicit processes to transfer knowledge within the firm. Translated, this basically are the intangible resources helping the firm utilize the tangible resources. Recently resource based work has focused on intangible assets (Makadok 2001).

Empirical findings support the relationship between resources and performance within the framework of Resourced Based View. Barney \& Clark (2007) says that discordant findings however few, have been reported in empirical studies. It is said that while RBV largely associates firm performance with intangible resources, the association may not always hold true empirically. Most contributions within the RBV take the individual resource as the relevant unit of analysis to study competitive advantage and performance. It ignores the complementarity and co-specialization nature of resources. Most researchers have recognized the role of firm based resources as sources of competitive advantage and superior performance in organizations. The RBV was relevant in the study since it focused on human capital and customer service as intangible resources of a firm which have the capability of giving an organization competitive advantage.

\subsubsection{Institutional Theory}

Philip Selznick (1948) wrote the first work on old institutional theory where he regarded organizations as entities that adjusted to environmental pressures. The new institutional was put forth by the works of Meyer and Rowan in 1977 which reasoned that formal structure develops in organizations as they observe institutional norms and beliefs from their environment. As an institution follows these beliefs, they become organized into the rules and practices which form organization's formal structure. Institutional theory concentrates on the things outside the organization that govern its existence such as rules and regulations, moral values of the society and policies governing the industry as well as governmental requirements (Scott, 2004). Kraft's Public Policy, reports that institutional theory is the art of making strategies that look up to the lawful aspects of the government structure (Kraft and Furlong, 2007).

According to Scott (2013), the institutional theory borrows from the society so as to stipulate how an organization will be set up and driven. It postulates that society is very important in shaping and validating an organization and also contributes to how it is run. Institutional theorists believe that members of society identify organizations based on norms and values that the organizations display. The applicability of this theory in this study stems from the fact that public hospitals are normally established in societies. It is the public being served that determines the legitimacy of the study being undertaken.

Dacin, Goodstein and Scott (2002) purport that after being gauged amongst other theories; institutional theory has been recognized for explaining how individuals and organizations behave. This being so, it has also been criticised for dwelling on the similarity of occurrences in an organization. Over time, since organizations are not static, they change due to the very nature of their existence as unique creations. The study agrees that organizations change over time even though they themselves initiate changes in nature and society. This theory was relevant in this study because according to Kraft and Furlong (2007), institutional theory focuses on policy-making that highlights the formal aspects of government structures. Public hospitals are government structures. 


\subsection{Empirical Review}

\subsubsection{Human Capital and Organizational Performance}

A study done by Bontis and Fitzenz, (2002) on 76 executives in 25 companies examined the backgrounds and consequent of managing human capital while using quantifiable and qualitative processes. The results produced a causal map on the basis of combined concepts gathered from variables such as information technology, human resources and organizational behaviour amongst others. The study recommended that organizations could benefit through understanding the driving forces in an organization that determine the usefulness of human capital capabilities. These will in turn assist in the allocation of human resources in the most effective way. The study focussed on human capital alone in an organization and failed to show how other resources in an organization are useful.

Liu et al (2010) carried a study on available approach to measuring human capital. The study focused on value creativity so as to more accurately and objectively measure human capital. The findings of the study assisted in shining the light on hurdles experienced during performance reviews as well challenges of being objective while measuring behaviour. The study focussed on one aspect of human capital, which is value creativity while this current study focussed on skills, motivation, training responsibilities and roles of employees in an organization.

A study done by Stiles and Kulvisaechana (2001), on organizational human capital growth and performance showed that there was a positive association between how an organization grows its human capital and how it performs. Variables considered in the study included recruitment, motivation and retaining best employees so as to leverage human capital as an investment and achieve competitive edge. The study focused on what the organization can do for the employees to improve performance but did not look at the employees' contribution.

\subsubsection{Customer Service and Organizational Performance}

A comparative study done by Afzal, Hossein, Maleki and Nasiripour (2016) on hospitals in 8 countries used identity, image, competitiveness, relationships and strategy as variables. Findings show that there are benefits of customer service in appealing to more patients and growing recognition. Hospitals under that study had considered deliberate schedules for hospital customer service since they believed in its positioning as a means of increasing their market segment through customer service. The study looked at what the hospitals could do to their clients but did not address the issue of how the clients would perceive those inputs.

Zigan, Macfarlane and Desombre (2007) used an inductive approach based on interviews with key informants in European hospitals on how intangible resources were used to gauge performance management. The findings indicated that hospital managers understand the significance of intangible resources and in particular regarding to organization of the human resources, formation of associations within and outside the organization and evaluation of individual performance. The research was exploratory in nature and hence did not address the key resources that impact performance.

Becerra and Badrinarayanan (2013), did a study on the influence of trust and brand identity by specifically looking at referrals, intentions and loyalty. The study concluded that dimensions of good customer service could be identified as customer recognition, consumer perception, frequent visits due to loyalty and customer confidence. They also argues that since customer service is a viable part of performance, studies related to it have more reputable theoretical logic when compared to other performance areas. This being the case, the study failed to look at qualities thought to be important to a customer such as reliability and empathy.

\subsection{Summary of Empirical Literature Review and Gaps}

Many scholars have devoted their researches on healthcare matters and especially in the advent of changing technology and knowledge. Governments have also invested heavily in improving the public health systems. Stakeholders who include customers and other financial contributors are assessing performance in these institutions and trying to see what affects this performance. The findings of the study will try to address the gap in the relationship between organizational intangible resources and performance.

\section{Conceptual Framework}

According to Jabareen (2009), conceptual framework is a network of interlinked concepts that together provide a comprehensive understanding of a phenomenon. In this study, the conceptual framework is made up of performance of public hospitals as a dependent variable while human capital and organizational capital form the independent variables. 


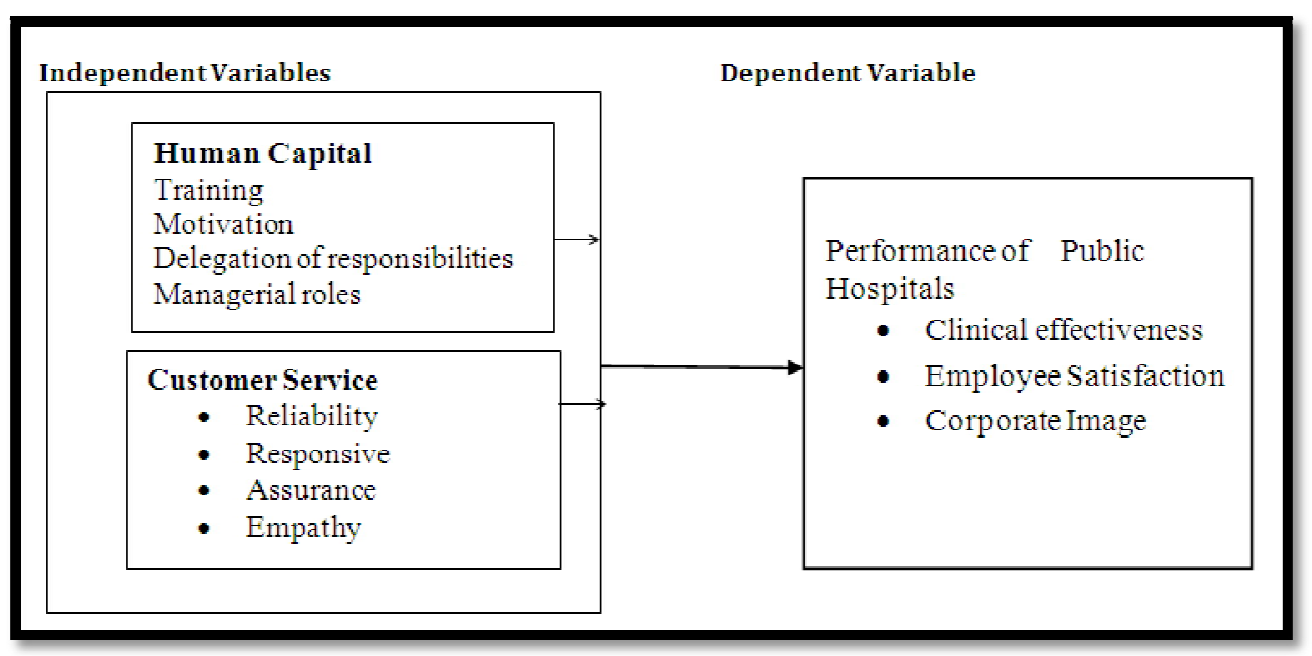

Figure 1: Conceptual Framework

Source: Author (2018)

\section{Methodology}

The study used explanatory and descriptive research designs which sought to address the questions of how human capital and customer service influences performance of public hospitals. Lambert and Lambert (2012) say that the goal of qualitative descriptive studies is a comprehensive, summarization in everyday terms, of specific events experienced by individuals or groups of individuals. Descriptive research was preferred because the researcher had no control over the variables (Mugenda \& Mugenda, 2003).

The study targeted 92 heads of departments drawn from 23 departments in four public hospitals in Kirinyaga Count, Kenya. According to Nzinga (2013) a public hospital comprises of 23 departments.

Each of the four public hospitals under study had twenty three departments chosen. Each of the department was represented by one head of department. Purposeful sampling was done since 23 departments were chosen and all the departmental heads participated in the study. This is in line with Mugenda and Mugenda, (2003) who says that a researcher can purposefully select respondents.

The instrument for data collection was closed ended questionnaires. According to Boynton and Greenhalgh (2004), questionnaires offer an objective means of collecting information about people's knowledge, beliefs, attitudes, and behaviour. According to Drost (2011) validity is the degree to which a test measures what it is supposed to measure. Construct validity was used in this study as it is concerned with detecting the presence or absence of one or more criteria considered to represent traits of interest. This was ensured through repeated discussions and reviews with the supervisor (Upagade \& Shende, 2008).

Cronbach's alpha reliability index was used in the study because it is designed for use with tests containing items that have no right answer where respondents are asked to rate the degree to which they agree or disagree with a statement on a particular scale.

The data collected was analyzed statistically using the SPSS version 17. Errors were controlled by making sure that the sample size was sufficient to sense a real difference if it truly existed. The relationship between independent and dependent variables was established using correlation and regression approaches.

The regression model took the form of

$Y=\beta_{0}+\beta_{1} X_{1}+\beta_{2} X_{2}+e$

Where $\mathrm{Y}=$ performance of public hospitals

$\beta_{1}$ and $\beta_{2}$ are regression coefficients

$\mathrm{X}_{1}=$ Human capital

$\mathrm{X}_{2}=$ Customer service

$\mathrm{E}=$ error term

The model helped the researcher to determine the linear connection between two or more variables in order to predict information or offer causal inference (Campbell \& Campbell, 2008). Tables were used for visual representation of the key findings.

\section{Data Analysis, Presentation and Discussion}

\subsection{Response rate}

The study distributed 92 questionnaires and all of them were received. Mugenda and Mugenda (2003), indicate that a $50 \%$ response rate is satisfactory to be used in a study. 


\subsection{Inferential Analysis}

The study used model summary, ANOVA and multiple linear regression models for inferential statistics as shown in the table below.

According to table 1 below, the adjusted $\mathrm{r}$ was 0.911 implying that $91.1 \%$ of the variation in performance of public hospitals is accounted for by the model while $8.9 \%$ is accounted for by other aspects outside the study. This implies that human capital and customer service accounted for variations of performance of public hospitals in Kirinyaga County by $91.1 \%$. While analysing ANOVA the $F(2,90)$ statistics 116.275 .549 with a p value of $.000 \varangle 0.05$. This implies that the model used was statistically significant and hence can be used for further inferential analysis.

The regression coefficient in table 1 below gives a summary of the extent to which the value of independent variables contributes to the value of the dependent variable as well as the level of significance of the study variables. From the tables, human capital had regression coefficient of $\beta_{1}=0.205$ : $\mathrm{P}<0.05$. This means that the variable was found to be statistically significant on performance of public hospitals. It implies that a unit increase of human capital will result to an increase of 0.205 in performance of public hospitals. Customer service had coefficient of $\beta_{2}=.279<0.05$. It implies that a unit increase of customer service will result to an increase of 0.279 in performance of public hospitals in Kirinyaga County.

\begin{tabular}{|c|c|c|c|c|c|}
\hline \multicolumn{6}{|c|}{ Model Summary } \\
\hline \multicolumn{2}{|l|}{ Model } & $\mathbf{R}$ & R Square & $\begin{array}{l}\text { Adjusted R } \\
\text { Square }\end{array}$ & $\begin{array}{l}\text { Std. Error Of } \\
\text { The Estimate }\end{array}$ \\
\hline \multicolumn{2}{|l|}{1} & 0.956 & 0.914 & 0.911 & 0.11578 \\
\hline \multicolumn{6}{|c|}{ Predictors: (Constant), Customer Service, Human Capital } \\
\hline \multicolumn{6}{|c|}{ Anova } \\
\hline Model & $\begin{array}{l}\text { Sum Of } \\
\text { Squares }\end{array}$ & Df & Mean Square & $\mathrm{F}$ & Sig. \\
\hline Regression & 6.235 & 2 & 1.558 & 116.275 & 0 \\
\hline Residual & 0.583 & 90 & 0.007 & & \\
\hline Total & 6.818 & 92 & & & \\
\hline Dependent Variable & \multicolumn{5}{|c|}{ Performance } \\
\hline Predictors & & Constan & Customer Ser & ce, Human Ca & \\
\hline \multicolumn{6}{|c|}{ Coefficients } \\
\hline \multirow[t]{2}{*}{ Model } & \multicolumn{2}{|c|}{$\begin{array}{l}\text { Unstandardized } \\
\text { Coefficients }\end{array}$} & $\begin{array}{c}\text { Standardized } \\
\text { Coefficients }\end{array}$ & \multirow[t]{2}{*}{$\mathrm{T}$} & \multirow[t]{2}{*}{ Sig. } \\
\hline & B & Std. Error & Beta & & \\
\hline (Constant) & 0.036 & 0.119 & & 0.299 & 0 \\
\hline Human Capital & 0.205 & 0.024 & 0.265 & 8.359 & 0 \\
\hline Customer Service & 0.279 & 0.025 & 0.375 & 11.313 & 0 \\
\hline
\end{tabular}

Table 1: Inferential Analysis

Based on the findings on table 1 above, all variables were statistically significant and can be summarised using the equation $\mathrm{Y}=0.36+0.205 \mathrm{X}_{1}+.279 \mathrm{X}_{2}+\mathrm{e}$

\section{Findings, Conclusions and Recommendations}

\subsection{Findings and Testing of Hypothesis}

The study sought to determine the effect of human capital in performance of public hospitals in Kirinyaga County, Kenya. The study found out that human capital was a positive statistically significant effect on performance of public hospitals. A hypothesis had been formulated with the assumption that there is no significant effect of human capital on performance of public hospitals in Kirinyaga County. Table 1 above shows the positive significance and hence the study rejected the null hypothesis.

The study found out that customer service had the greatest contribution in performance of public hospitals in Kirinyaga County hence concluded that indeed customer service was important. A hypothesis had been formulated with the assumption that there is no significant effect of customer service on performance of public hospitals in Kirinyaga County. The findings of the study rejected the null hypothesis. 


\subsection{Conclusion}

The aim of this study was to establish the influence of human capital and customer service on the performance of public hospitals in Kirinyaga County, Kenya. All the variables used for this study proved to have a positive effect on the performance of public hospitals in Kirinyaga Count, Kenya and therefore the study concluded that the variables were significant. It was also concluded that they achieved performance of public hospitals when working together to influence each and not just as individual variables. This is consistent with Kenya's vision 2030 flagship projects of human resource strategy and revitalization of the health management Information system and a pillar in the Big Four agenda in Kenya.

\subsection{Recommendations for Policy and Practice}

The study recommends to the County Government to enhance, enforce and strengthen policies on procurement of visionary skilled and competent human resources for health. It also recommends improvement of policies meant to retain and maintain human resource as a motivational strategies. The study further recommended that hospital management should give directions on development of customer relations and also improve was on handling customer complaints.

\section{References}

i. Afzall,E., Hossein,M., Maleki , M.R.\& Nasiripoura.A. (2016) Comparative study of customer service in Iranian public hospitals and some other public hospitals in selected countries Biosciences Biotechnology Research Asia, March 2016. Vol. 13(1), 327-333

ii. Barney J.B. \& Clark D.N, (2007) Resource-based theory: creating and sustaining competitive advantage University Press, Oxford

iii. Becerra, E., \& Badrinarayanan, V. (2013). The influence of customer service trust and customer service identification on customer service evangelism. Journal of Product \& Customer Service Management, 22(5/ 6), 371-383

iv. Becker, G. S. (1994). Human capital revisited. In Human Capital: A Theoretical and Empirical Analysis with Special Reference to Education (3rd Edition) (pp. 15-28). The University of Chicago press.

v. Berg, M., Meijerink, Y., Gras, M., Goossensen, A., Schellekens, W., Haeck, J., and Kingma, H. (2005). Feasibility first: Developing public performance indicators on patient safety and clinical effectiveness for Dutch hospitals. Health Policy, 75(1), 59-73.

vi. Boshoff, C. \& Gray, B. (2004). The relationships between service quality, customer satisfaction and buying intentions in the private hospital industry South African Journal of Business Management, 35(4)

vii. Bontis, N. \& Fitz-enz, J. (2002). Intellectual capital ROI: a causal map of human capital antecedents and consequents. Journal of Intellectual Capital, 3 (3), pp. 223-247.

viii. Boynton, P. M., \& Greenhalgh, T. (2004). Hands-on guide to questionnaire research: Selecting, designing, and developing your questionnaire. BMJ: British Medical Journal, 328(7451), 1312.

ix. Campbell, D. \& Campbell, S. (2008) Introduction to regression and data analysis. Satlab Workshop Series

x. Catherine B., Aaron M., Daniel M., and Arin D. (2014). Health policy project Devolution of healthcare in Kenya assessing county health system readiness in Kenya: A Review of Selected Health InputsAsretrievedfromhttps:/ / www.Healthpolicyproject.com/ pubs/479_KenyaPETSCountyReadinessFINAL.pdf on 01.02 .2018

xi. Dacin, M. T., Goodstein, J., \& Scott, W. R. (2002). Institutional theory and institutional change: Introduction to the special research forum. Academy of Management Journal, 45(1), 45-56.

xii. Drost, E. A. (2011). Validity and reliability in social science research. Education Research and Perspectives, 38(1), 105

xiii. Healy J, McKee M. (2002). The role and function of hospitals. In: Mckee M, Healy J, Eds. Hospitals in a Changing Europe. Buckingham, Open University Press, 2002.

xiv. Jabareen, Y. (2012). Building a conceptual framework: Philosophy, definitions, and procedure. InternationalJournalofQualitativeResearchasretrievedfromhttps:/ / ejournals.library.ualberta.ca/ index.php/ IJQM/ arti cle/ viewFile/ 6118/ 5892 on 06.12 .2016

xv. Lambert, V. A., \& Lambert, C. E. (2012). Qualitative descriptive research: An acceptable design. Pacific Rim International Journal of Nursing Research, 16(4), 255-256

xvi. Liu, L., Timohty. V. and Gao, Y. (2010). Approaches of resources -based view. Empirical research in banking. International Journal of Applied Economics and Finance, 4(4)

xvii. Makadok, R. (2001). Towards a synthesis of the resource-based and dynamic-capability views of rent creation. Strategic Management Journal, 22: 387-401.

xviii. Marshall G. \& Murdoch I. (2001). Service quality in consulting marketing engineers. International Journal of Construction Mark. 2001; 3(1):41-9.

xix. Muga, R., Kizito, P., Mbayah, M., \& Gakuruh, T. (2005). Overview of the health system in Kenya. Demographic and health surveys. http:/ / www. Measured com/ pubs/ pdf/ SPA 8/ 02 (accessed February 16, 2016).

xx. Mugenda, O. M., \& Mugenda, G. A. (2003). Research methods quantitative and qualitative approaches. Nairobi: ACTS.

xxi. Myers, J. L., Well, A., \& Lorch, R. F. (2010). Research design and statistical analysis. Routledge.

xxii. Nzinga, J., Mbaabu, L., \& English, M. (2013). Service delivery in Kenyan district hospitals-what can we 
xxiii. Okoth, J. (2013). Influence of tangible resources on the performance of county health services, Kenya-

UON

xxiv. Peräkylä, A. (2011). Validity in research on naturally occurring social interaction. Qualitative Research, 365-382

xxv. Rafati,M; Zargar,S \& Dehghan,R.(2005). Case study of countries in the eastern Mediterranean region, Hospital Journal, 5(9): 48-55

xxvi. Scott, W. R. (2013). Institutions and organizations: Ideas, interests, and identities. Sage Publications.

xxvii. Stiles, P., \& Kulvisaechana, S. (2003). Human capital and performance: A literature review. DTI

xxviii. Sadiq Sohail, M. (2003). Service quality in hospitals: more favourable than you might think. Managing Service Quality: International Journal, 13(3), 197-206.

xxix. Upagade, V., \& Shende, A. (2012). Research methodology S. Chand and Company Ltd. New Delhi, India.

xxx. Zainal, Z. (2007). Case study as a research method, Jurnal Kemanusiaan, (9), 1-6 